\title{
Long-term changes in the properties of skin-derived fibroblasts following irradiation of the head and neck
}

\author{
THOMAS GEHRKE, AGMAL SCHERZAD, STEPHAN HACKENBERG, PASCAL ICKRATH, \\ PHILIPP SCHENDZIELORZ, RUDOLF HAGEN and NORBERT KLEINSASSER
}

\begin{abstract}
Department of Otorhinolaryngology, Head and Neck Surgery, University Hospital Würzburg, D-97080 Würzburg, Germany
\end{abstract}
Received November 16, 2016; Accepted March 3, 2017

DOI: $10.3892 / 01.2017 .6593$

\begin{abstract}
The tumor stroma performs an important role in carcinogenesis. It predominantly consists of fibroblasts and the connective tissue produced by them, and undergoes a multitude of interactions with the surrounding cancer cells. Since irradiation is part of the majority of therapeutic strategies for head and neck squamous cell carcinoma, more information regarding the effects of a previous irradiation on the tumor stroma is desirable. In the present study, fibroblasts were cultivated from human non-irradiated and pre-irradiated skin of the neck for $48 \mathrm{~h}$. Subsequently, analyses of cell viability, apoptosis, necrosis and motility were conducted via MTT assay, Annexin V/propidium iodide staining, electronic cell counting for 4 consecutive days, and scratch assay. Pre-irradiated fibroblasts exhibited a significantly slower growth rate as well as increased rates of apoptosis and necrosis. They also exhibited significantly decreased motility compared with non-irradiated fibroblasts. These results indicated the long-term effects of irradiation on fibroblasts, which may affect cancer recurrence in the irradiated region via the tumor stroma. More information, such as that regarding the secretory capacities of pre-irradiated fibroblasts, is required to evaluate the possible therapeutic implications of these findings.
\end{abstract}

\section{Introduction}

Cell biology and genetic studies indicate that tumor growth is not just determined by malignant cancer cells themselves, but also by the tumor stroma (1). Fibroblasts are non-vascular, non-inflammatory and non-epithelial cells of the connective tissue, and are the principal cellular component of the tumor stroma (2). They are embedded within the fibrillar matrix of the connective tissue and are, to a large extent, responsible for

Correspondence to: Dr Thomas Gehrke, Department of Otorhinolaryngology, Head and Neck Surgery, University Hospital Würzburg, 11 Josef Schneider Street, D-97080 Würzburg, Germany E-mail: thomas-gehrke@web.de

Key words: fibroblast, tumor stroma, irradiation, skin-derived, long-term its synthesis (2). It is becoming increasingly evident that fibroblasts are also prominent modifiers of cancer progression $(3,4)$. There is evidence that a subpopulation of fibroblasts, termed cancer-associated fibroblasts (CAFs), are important promoters of tumor growth and progression (5). CAFs may induce epithelial-mesenchymal transition in epithelial tumor cells, a key factor in the invasion of squamous cell carcinoma (6).

The role of the tumor stroma on cancer progression has also been investigated for head and neck squamous cell carcinoma (HNSCC). HNSCCs are among the most common malignancies worldwide (7). In the USA, it is estimated that $\sim 500,000$ new cases of HNSCC are diagnosed per year, equating to an incidence of 14 per 100,000 inhabitants (8). Despite the implementation of multi-modal treatment strategies, including surgery, radiation and chemotherapy, the survival rates have not improved significantly over the past several decades (9). For HNSCC, radiation is part of the majority of therapeutic strategies, either as a primary therapy or as adjuvant radiation following surgery (10). The effects of radiation on patients are widely known (11-13); short-term effects mainly comprise damage to the skin and mucosa in the irradiated region, while long-term effects include xerostomia and an increased risk of secondary malignancies (14).

However, the effects of a previous irradiation on the tumor stroma are largely unknown. In vitro, it has been demonstrated that CAFs exhibit no significant changes in proliferation or growth when exposed to radiation (15), while another study indicated an enhanced capability of irradiated fibroblasts to promote survival of co-cultured cancer cells (16). In these previous studies, however, the irradiation was delivered in vitro, and the long-term effects on the irradiated tumor stroma were not investigated.

Our previous study demonstrated decreased viability of tumor cells and decreased interleukin (IL)-8 secretion when the tumor cells were co-cultured with fibroblasts from pre-irradiated human skin, as compared with skin-derived fibroblasts from non-irradiated patients (17). This raises the question of whether an irradiation of the head and neck during cancer therapy changes the properties of fibroblasts on a long-term basis, and what these changes consist of.

The primary objective of the present study was to evaluate the long-term effects of irradiation during therapy for HNSCC on skin-derived human fibroblasts compared with fibroblasts from non-irradiated skin, in terms of viability, apoptosis, necrosis, cell expansion and motility. 


\section{Materials and methods}

Acquisition and culture of fibroblasts. Fibroblasts were obtained from skin samples from 20 patients undergoing neck surgery at the University Hospital Würzburg, Germany, between October 2012 and November 2013. Of the 20 patients, 10 had been treated with intensity-modulated irradiation with 60-70 Gy for 6 weeks during head and neck cancer therapy 6-18 months previously (Table I). The other 10 patients underwent neck surgery for other reasons than cancer (Table I). Approval was obtained from the Ethics Committee of the Medical Faculty, University of Würzburg (approval no. 12/06), and informed consent was obtained from all patients involved. Tissue preparation was performed as described in our previous study (17), which included a modification of the protocol described by Vangipuram et al (18). In summary, the skin samples were cleared of fat and cut into small pieces of 2-3 mm, which were then seeded on 6 -well plates. After 60 min of culture without medium at $37^{\circ} \mathrm{C}$ and $5 \% \mathrm{CO}_{2}$, the tissue pieces had sufficiently adhered to the bottom of the plates, such that Dulbecco's modified Eagle medium (DMEM; Invitrogen; Thermo Fisher Scientific, Inc., Waltham, MA, USA) with $10 \%$ fetal calf serum (Biochrom, Ltd., Cambridge, UK), $100 \mathrm{U} / \mathrm{ml}$ penicillin and $100 \mu \mathrm{g} / \mathrm{ml}$ streptomycin [DMEM-expansion medium (DMEM-EM)] could be added without the pieces being washed away. From these tissue pieces, the fibroblasts grew out into the periphery. Every other day, the medium was replaced and passaging was performed when the cells had reached 70-80\% confluence; passaging was performed by trypsinization $(0.25 \%$ trypsin; Invitrogen; Thermo Fisher Scientific, Inc.), washing in PBS and seeding into new flasks or treatment wells.

Cell count. A total of $2 \times 10^{4}$ cells were incubated in DMEM-EM at $37^{\circ} \mathrm{C}$ with $5 \% \mathrm{CO}_{2}$ for 4 days, while electronically evaluating the cell number and cell viability each day using $\mathrm{CASY}^{\circledR}$ Technology (Innovatis AG, Reutlingen, Germany). Only cells labeled viable by the electronic counting were included in the analysis for the cell counting.

MTT assay. The MTT (Sigma-Aldrich; Merck KGaA, Darmstadt, Germany) colorimetric staining method according to Mosmann (19) was used to study the viability of cells. All wells were incubated with $1 \mathrm{ml}$ of MTT $(1 \mathrm{mg} / \mathrm{ml})$ for $5 \mathrm{~h}$ at $37^{\circ} \mathrm{C}$ with $5 \% \mathrm{CO}_{2}$. MTT was then removed and $1 \mathrm{ml}$ of isopropanol was added, followed by another incubation period of $1 \mathrm{~h}$ at $37^{\circ} \mathrm{C}$ with $5 \% \mathrm{CO}_{2}$. Color changes due to the conversion of MTT to blue formazan dye were measured using a multi-plate reader (Titertek Multiskan PLUS MK II; Labsystems Diagnostics Oy, Helsinski, Finland) at a wavelength of $570 \mathrm{~nm}$.

Annexin V/propidium iodide staining. A BD Pharmingen ${ }^{\mathrm{TM}}$ APC Annexin V kit (BD Biosciences, Franklin Lakes, NJ, USA) was used to evaluate apoptosis. Cells in suspension and adherent cells were harvested and washed twice with PBS, followed by resuspension in 1:10 binding buffer (0.1 M HEPES, $\left.\mathrm{pH} 7.4,1.4 \mathrm{M} \mathrm{NaCl}, 25 \mathrm{mM} \mathrm{CaCl}_{2}\right)$ at a density of $1 \times 10^{6}$ cells $/ \mathrm{ml}$. Aliquots of this cell suspension ( $100 \mu \mathrm{l} ; 1 \times 10^{5}$ cells) were then transferred to a $5 \mathrm{ml}$ culture tube. Propidium iodide $(5 \mu \mathrm{l})$ and Annexin V-APC $(5 \mu \mathrm{l})$ were added to each aliquot. Following
15 min of incubation at room temperature in the dark, the cells were resuspended with $400 \mu 1$ 1:10 binding buffer. A FACScanto flow cytometer (BD Biosciences) was used to analyze the samples. Propidium iodide staining indicated cells with damaged membranes.

Scratch assay. A scratch assay was used to analyze cell migration capability. Fibroblasts $\left(1 \times 10^{5}\right.$ cells $\left./ \mathrm{ml}\right)$ were cultivated in a 12 -well round-bottom plate at $37^{\circ} \mathrm{C}$ and $5 \% \mathrm{CO}_{2}$. After $24 \mathrm{~h}$, a straight-line wound was induced with a sterile 1-ml pipette tip. Subsequently, the culture plates were washed with PBS and images were captured (day 0) with a Leica DMI 4000B Inverted Microscope at x40 magnification (Leica Microsystems $\mathrm{GmbH}$, Wetzlar, Germany). The cells were then incubated for a further $24 \mathrm{~h}$ at $37^{\circ} \mathrm{C}$ with $5 \% \mathrm{CO}_{2}$, before images of the plates were captured (day 1) and the percentage of the wound closure was evaluated. This was repeated after another $24 \mathrm{~h}$ of incubation (day 2). The calculation of the area of the wound closure was investigated using Image J software (version $1.43 \mathrm{u}$, open source product) at day 0 , day 1 and day 2 .

Statistical analysis. The data collected was transferred to standard spreadsheets and statistically analyzed using GraphPad Prism Software (version 6.0; GraphPad Software, Inc., La Jolla, CA, USA). The Gaussian distribution was tested via first column analysis. Students t-test followed by Tukey's multiple comparison test was used for statistical analysis. Data are presented as the mean \pm standard deviation, unless otherwise stated. $\mathrm{P}<0.05$ was considered to indicate a statistically significant difference.

\section{Results}

Cell count. In a consecutive cell count for 4 days, non-irradiated fibroblasts exhibited a constant increase in cell number between days 0 and 4 , reaching a median of $1.15 \times 10^{5}$ cells on day 4. Fibroblasts from pre-irradiated tissue only had a minor increase in cell number, reaching a plateau on day 3 with a median of $4.96 \times 10^{4}$ cells (Fig. 1). The differences between the irradiated and non-irradiated groups were statistically significant on days 2,3 and $4(\mathrm{P}=0.0002, \mathrm{P}=0.0001$ and $\mathrm{P}=0.0001$, respectively). At day 4, non-irradiated fibroblasts had a median cell viability of $76 \%$, whereas pre-irradiated fibroblasts had a median viability of $66 \%$.

MTT assay. Viability of non-irradiated and pre-irradiated fibroblasts was analyzed by MTT assay (Fig. 2). The assay revealed significantly lower cell viability for fibroblasts cultured from pre-irradiated skin tissue compared with non-irradiated fibroblasts $(\mathrm{P}=0.0061)$.

Annexin V/propidium iodide analysis. The Annexin V/propidium iodide analysis was used to determine differences in the rates of apoptosis, necrosis and viability between pre-irradiated fibroblasts and non-irradiated fibroblasts (example shown in Fig. 3). Significantly higher rates of apoptosis $(\mathrm{P}=0.0080)$ and necrosis $(\mathrm{P}=0.0019)$ were observed in pre-irradiated fibroblasts compared with non-irradiated fibroblasts (Fig. 4). A lower percentage of viable cells in pre-irradiated fibroblasts ( $\mathrm{P}=0.0002$; Fig. 4) was also observed compared with 
Table I. Data and characteristics of the patients.

\begin{tabular}{|c|c|c|c|c|c|}
\hline Patient no. & Sex & Age, years & $\begin{array}{l}\text { Primary tumor site/ } \\
\text { reason for surgery }\end{array}$ & $\begin{array}{l}\text { Radiation } \\
\text { dose, Gy }\end{array}$ & $\begin{array}{l}\text { Concurrent } \\
\text { chemotherapy }\end{array}$ \\
\hline 1 & Male & 63 & Hypopharynx & 70 & Yes \\
\hline 2 & Male & 54 & Oropharynx & 66 & No \\
\hline 3 & Male & 59 & Larynx & 60 & No \\
\hline 4 & Female & 72 & Hypopharynx & 69 & Yes \\
\hline 5 & Male & 57 & Larynx & 60 & No \\
\hline 6 & Male & 61 & Hypopharynx & 69 & Yes \\
\hline 7 & Female & 61 & Oropharynx & 69 & Yes \\
\hline 8 & Female & 70 & Larynx & 60 & No \\
\hline 9 & Male & 59 & Oropharynx & 69 & Yes \\
\hline 10 & Male & 65 & Hypopharynx & 66 & No \\
\hline 11 & Female & 46 & Parotidectomy & $\mathrm{n} / \mathrm{a}$ & $\mathrm{n} / \mathrm{a}$ \\
\hline 12 & Female & 56 & Cervical cyst & $\mathrm{n} / \mathrm{a}$ & $\mathrm{n} / \mathrm{a}$ \\
\hline 13 & Male & 39 & Cervical cyst & $\mathrm{n} / \mathrm{a}$ & $\mathrm{n} / \mathrm{a}$ \\
\hline 14 & Female & 65 & Parotidectomy & $\mathrm{n} / \mathrm{a}$ & $\mathrm{n} / \mathrm{a}$ \\
\hline 15 & Male & 72 & Cervical cyst & $\mathrm{n} / \mathrm{a}$ & $\mathrm{n} / \mathrm{a}$ \\
\hline 16 & Male & 81 & Cervical cyst & $\mathrm{n} / \mathrm{a}$ & $\mathrm{n} / \mathrm{a}$ \\
\hline 17 & Male & 59 & Parotidectomy & $\mathrm{n} / \mathrm{a}$ & $\mathrm{n} / \mathrm{a}$ \\
\hline 18 & Female & 66 & Cervical cyst & $\mathrm{n} / \mathrm{a}$ & $\mathrm{n} / \mathrm{a}$ \\
\hline 19 & Male & 69 & Parotidectomy & $\mathrm{n} / \mathrm{a}$ & $\mathrm{n} / \mathrm{a}$ \\
\hline 20 & Male & 62 & Parotidectomy & $\mathrm{n} / \mathrm{a}$ & $\mathrm{n} / \mathrm{a}$ \\
\hline
\end{tabular}

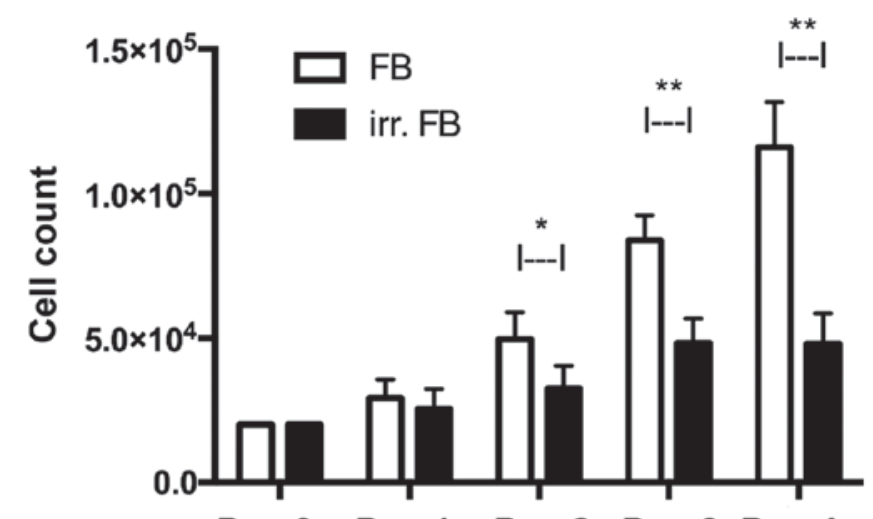

Figure 1. Consecutive electronic cell count for 4 days. There was a constant increase in cell numbers in the non-irradiated fibroblasts and only a minor increase in pre-irradiated fibroblasts. The higher cell numbers in non-irradiated vs. irradiated fibroblasts were statistically significant on days 2, 3 and 4 $\left({ }^{*} \mathrm{P}=0.0002\right.$ and $\left.^{* *} \mathrm{P}=0.0001\right) . \mathrm{FB}$, fibroblast; irr., irradiated.

non-irradiated fibroblasts, thus confirming the results of the MTT-assay.

Scratch assay. The scratch assay was used to evaluate cell migration into a wound area in monolayer conditions. When creating the wound on day 0 , no statistically significant difference was observed between the two groups. Following periods of 24 and $48 \mathrm{~h}$, respectively, at $37^{\circ} \mathrm{C}$ and $5 \% \mathrm{CO}_{2}$, the wound closure was measured and compared between the two groups. The pre-irradiated fibroblasts showed significantly slower wound closure compared with non-irradiated fibroblasts on

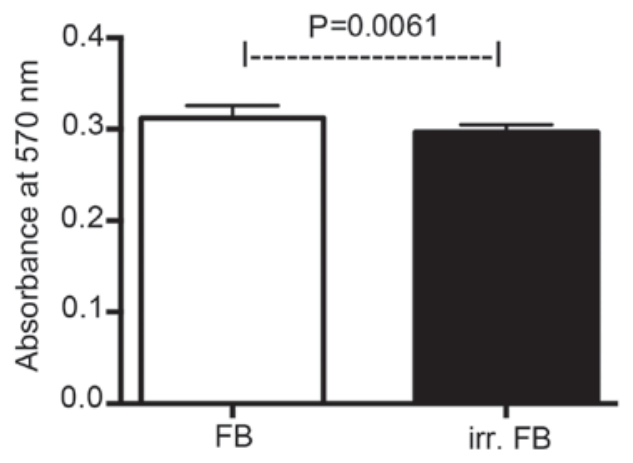

Figure 2. MTT assay. There was a statistically significant decrease in cell viability in pre-irradiated fibroblasts compared with non-irradiated fibroblasts $(\mathrm{P}=0.0061)$. FB, fibroblast; irr., irradiated.

day 1 and day $2(\mathrm{P}=0.0001$ and $\mathrm{P}=0.0027$, respectively), thus indicating reduced cell motility (Figs. 5 and 6).

\section{Discussion}

The present study focused on the effects of a previous radiation on the properties of skin-derived fibroblasts. Tumor progression has been recognized as the product of an evolving crosstalk between different cell types within the tumor and its surrounding supporting tissue, or tumor stroma (20). The immune cells, capillaries, basement membrane, activated fibroblasts and extracellular matrix surrounding the cancer cells constitute the tumor stroma (21). Fibroblasts comprise a major component of the tumor stroma, and numerous studies have indicated a prominent role for these cells in 

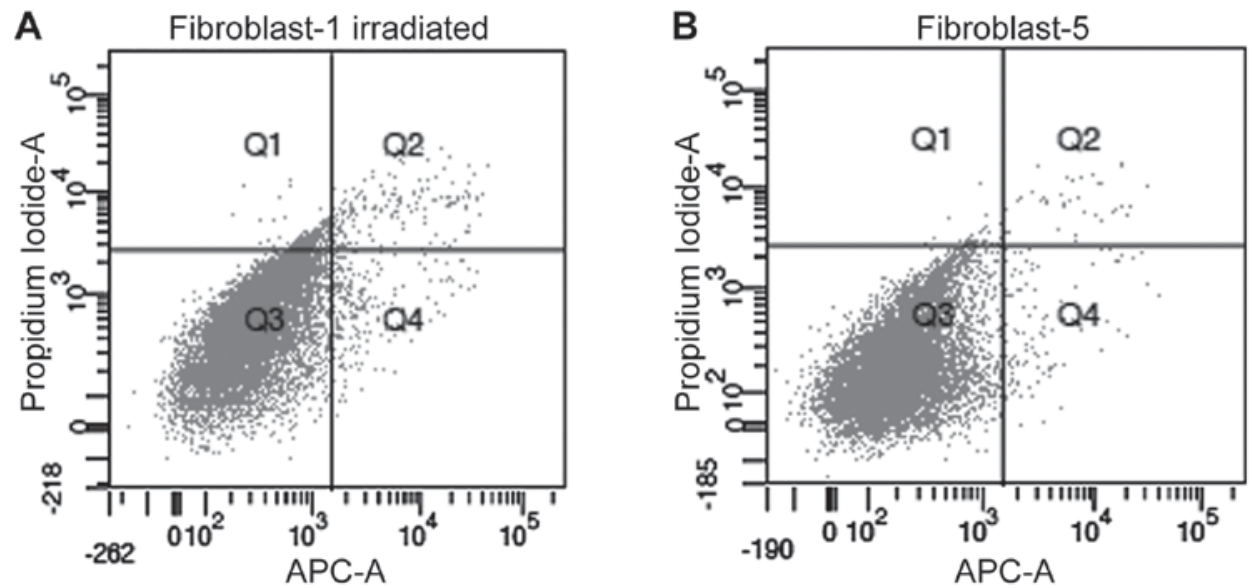

Figure 3. Annexin V-propidium iodide assay. Representative results from (A) non-irradiated fibroblasts and (B) pre-irradiated fibroblasts are shown. Q1,\% of damaged cells; Q2,\% of necrotic cells; Q3,\% of viable cells; Q4, \% of apoptotic cells. APC-A, allophycocyanin-A.

A
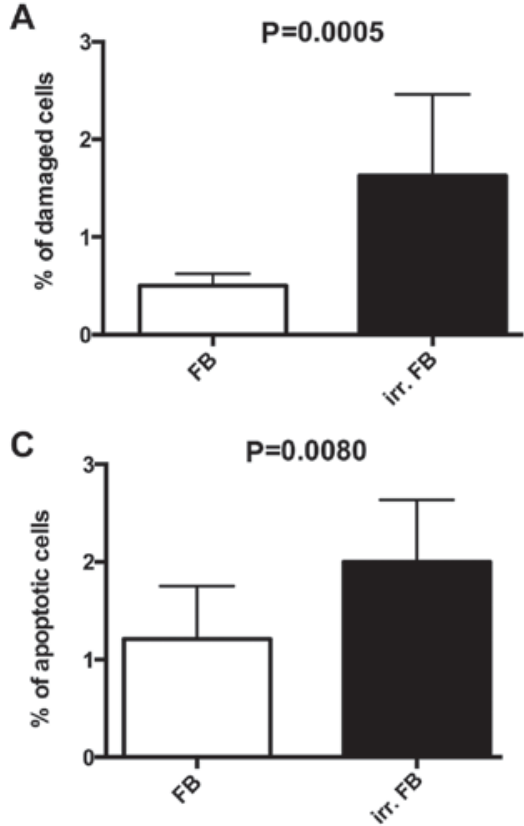

B

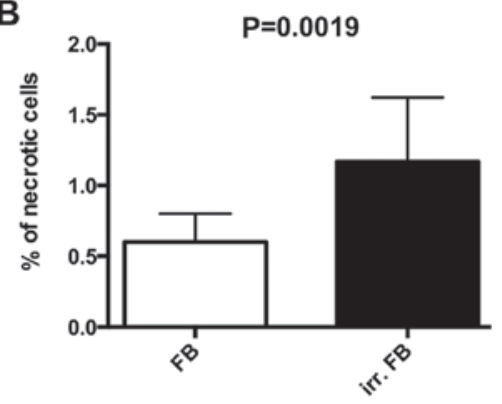

D

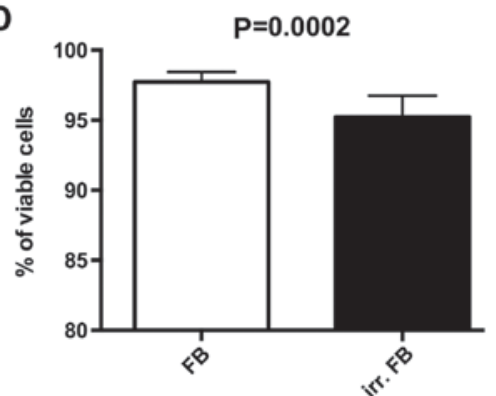

Figure 4. Statistical evaluation of the Annexin V-propidium iodide assay. There were increased rates of $(\mathrm{A})$ damaged cells $(\mathrm{P}=0.0005)$, $(\mathrm{B})$ necrotic cells $(\mathrm{P}=0.0019)$, and $(\mathrm{C})$ apoptotic cells $(\mathrm{P}=0.0080)$, as well as $(\mathrm{D})$ a lower percentage of viable cells $(\mathrm{P}=0.0002)$ in pre-irradiated fibroblasts compared with non-irradiated fibroblasts. FB, fibroblast; irr., irradiated.

cancer progression and metastasis $(2,22)$. CAFs have been established as key components of tumor progression, and increasing information indicates that they possibly contribute to a wide range of fibrotic stromal programs of numerous different tumors $(23,24)$. In the context of a highly dynamic and injurious tissue microenvironment, including damage induced by chemotherapy or radiotherapy, CAFs may represent a resistant stromal cell type that may be involved in tumor relapse (25).

Particularly in regard to relapsing cancer, information about whether previous radiation changes the properties and behavior of fibroblasts is desirable. It is already known that cells exposed to radiation may survive, but give rise to progeny that carry heritable damage (26). This damage may become lethal during many generations of division cycles of the originally irradiated progenitor cell (27,28). Gorgojo and Little (29) previously described the expression of lethal mutations in the progeny of irradiated mammalian cells, thus showing an effect on surviving cells a long time after the irradiation was administered. Chang and Little $(27,28)$ reported delayed reproductive deaths in cell clones surviving irradiation, several generations following therapy. However, these experiments were performed on established cell lines grown and irradiated in vitro, and the relevance of lethal mutations to irradiation of cells in vivo has been uncertain (30). Chatterjee et al (30) stated that the reduction in the long-term viability of irradiated cell populations appears to be dose-dependent and is most noticeable following large doses of radiation. In the present study, fibroblasts derived from pre-irradiated skin showed significantly lower viability and slower cell growth compared with skin-derived fibroblasts from non-irradiated patients, thereby confirming the in vitro data available in the literature. 
Day 0

FB
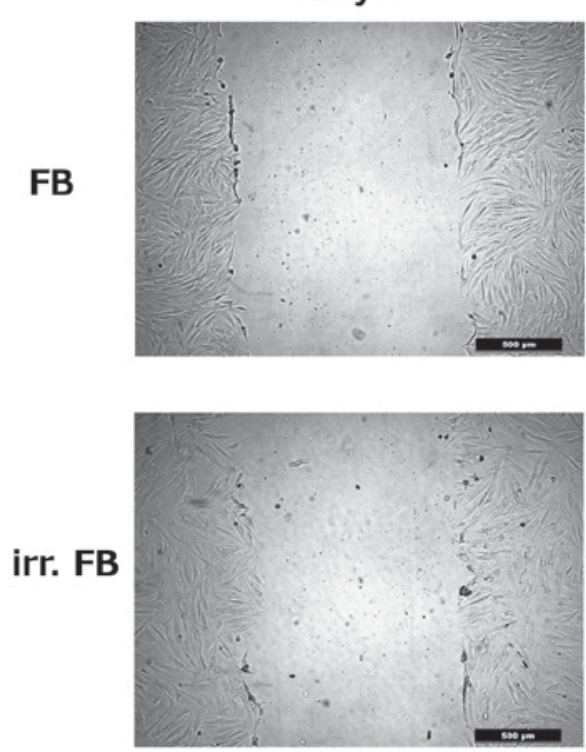

Day 1
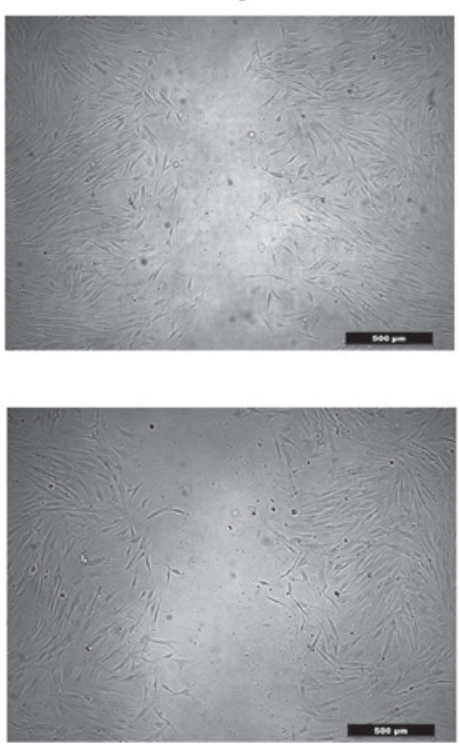

Day 2
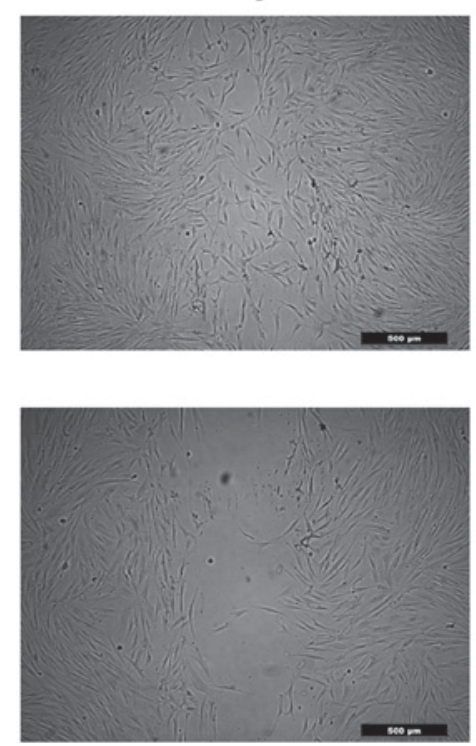

Figure 5. Representative images of the scratch assay. Upper row, non-irradiated fibroblasts. Lower row, pre-irradiated fibroblasts. On day 0 , the wound area was the same in the two groups (left). On day 1, a lesser degree of wound closure was observed in pre-irradiated fibroblasts than non-irradiated fibroblasts (middle). On day 2 , the wound area in non-irradiated fibroblasts was almost completely closed, while the cell-free area was still clearly visible in the pre-irradiated fibroblasts (right). Scale bar, $500 \mu \mathrm{m}$. FB, fibroblast; irr., irradiated.

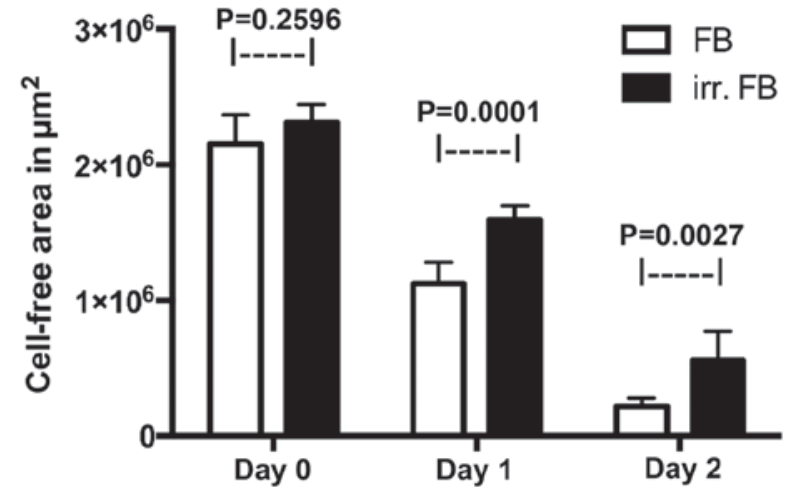

Figure 6. Statistical analysis of the scratch assay. There was a significantly lower percentage of wound closure on days 1 and 2 in the pre-irradiated fibroblasts compared with non-irradiated fibroblasts. FB, fibroblast; irr., irradiated.

Contrary to the aforementioned studies, the cells used in the present study were primary human fibroblasts from skin irradiated 6-18 months before, thus more accurately representing the real physiological effects of irradiation in vivo.

The levels of apoptosis and necrosis were elevated in the pre-irradiated fibroblasts in the present study. This indicated that there is more than one mechanism by which irradiation damages surviving cells. O'Reilly et al (31) reported a constant frequency of non-lethal mutations occurring per cell division, indicating a permanent genetic change induced by radiation. Kadhim et al (32) also favored this hypothesis, speculating that this mechanism may lead to cell death by an active process such as apoptosis, rather than necrosis. O'Reilly et al (31) also demonstrated abnormalities in irradiated cultures a number of generations after initial exposure, including convolution of the nuclear envelope, increased incidence of microvilli and lysosomal accumulations, which are characteristic of apoptosis rather than necrosis. However, early senescence as an alternative cause of radiation-induced changes has been discussed for mesenchymal stem cells (MSCs) and fibroblasts $(33,34)$.

In the present study, the scratch assay revealed reduced motility of pre-irradiated fibroblasts. RodriguezMenocal et al (35) demonstrated decreased motility and migration capability of MSCs in an irradiated murine delayed wound healing model. Henke et al (36) reported decreased motility and contractility in prostate CAFs, in their study associated with an increase of focal adhesion kinase. By contrast, Nicolay et al (37) found no changes in the actin cytoskeleton or in the functional motility of irradiated MSCs and fibroblasts. However, whether the delayed wound healing observed in the present study is the result of reduced motility due to radiation-induced genetic changes or a consequence of the reduced cell division remains unclear.

The effects of the radiation-induced changes observed in the fibroblasts in the present study of tumor cells differed from the data available in previous studies. Kamochi et al (38) presented data indicating that irradiated fibroblasts promote growth and invasion of co-cultured HNSCC. Other studies also reported of increased invasiveness of pancreatic and mammalian tumor cells co-cultured with irradiated fibroblasts $(39,40)$. However, in all these studies the radiation was administered in vitro to the fibroblasts, so the long-term effects could not be examined. The use of fibroblasts from human skin, which has been exposed to therapeutic irradiation a number of months prior, appears to be more comparable to the physiological conditions in vivo. Using this approach, previous studies have already demonstrated a decrease in viability of HNSCC co-cultured with pre-irradiated fibroblasts (17). In addition, fibroblasts from pre-irradiated human skin decreased the secretion of IL- 8 by HNSCC cells in a co-culture of these two cell types (17).

A notable drawback of the present study was that functional analysis regarding cytokine secretion and protein 
synthesis was not included. A quantitative evaluation of the secretory profile of the fibroblasts with or without radiation may elucidate the mechanisms behind the changes observed in the present study. In particular, ILs such as IL-6 and IL-8 have been shown to be prominent modifiers of cancer cell behavior (41-44). Whether the amount of these ILs produced by fibroblasts changes following irradiation, however, has not been investigated thus far. These analyses will be part of future studies at our institution.

In conclusion, previous irradiation is associated with changes in the properties of fibroblasts derived from human skin in the irradiated area. Reduced cell viability, increased rates of apoptosis and necrosis, slower cell growth and reduced cell motility may be demonstrated. Since the effects of these radiation-induced changes of the fibroblasts on tumor cells have already been demonstrated, more information regarding the genetic and secretory alterations of the fibroblasts are warranted to fully elucidate the long-term effects of radiation. These radiation-induced changes in fibroblasts (and, therefore, the tumor stroma) may be a possible novel target for therapeutic strategies for recurring cancer, and therefore require additional investigation.

\section{Acknowledgements}

The present study was supported in part by the Rudolf Bartling Foundation.

\section{References}

1. Kalluri R: Basement membranes: Structure, assembly and role in tumour angiogenesis. Nat Rev Cancer 3: 422-433, 2003.

2. Kalluri $R$ and Zeisberg M: Fibroblasts in cancer. Nat Rev Cancer 6: 392-401, 2006.

3. Tlsty TD and Hein PW: Know thy neighbor: Stromal cells can contribute oncogenic signals. Curr Opin Genet Dev 11: 54-59, 2001.

4. Elenbaas B and Weinberg RA: Heterotypic signaling between epithelial tumor cells and fibroblasts in carcinoma formation. Exp Cell Res 264: 169-184, 2001.

5. Mueller MM and Fusenig NE: Friends or foes - bipolar effects of the tumour stroma in cancer. Nat Rev Cancer 4: 839-849, 2004.

6. Higashikawa K, Yoneda S, Taki M, Shigeishi H, Ono S, Tobiume K and Kamata N: Gene expression profiling to identify genes associated with high-invasiveness in human squamous cell carcinoma with epithelial-to-mesenchymal transition. Cancer Lett 264: 256-264, 2008.

7. Torre LA, Bray F, Siegel RL, Ferlay J, Lortet-Tieulent J and Jemal A: Global cancer statistics, 2012. CA Cancer J Clin 65 87-108, 2015.

8. Parkin DM, Bray F, Ferlay J and Pisani P: Global cancer statistics, 2002. CA Cancer J Clin 55: 74-108, 2005.

9. Chan GG, Tai BC, Liang S, Lim DT and Soo KC: Squamous cell carcinoma of the head and neck (HNSCC)-multi-modality treatment and impact on survival. Asian J Surg 25: 35-40, 2002.

10. Ganzer U and Gobel U: Modern treatment strategies in head and neck tumors in childhood and adolescence-a review. Laryngol Rhinol Otol (Stuttg) 63: 113-119, 1984.

11. Million RR, Parsons JT and Mendenhall WM: Effect of radiation on normal tissues in the head and neck. Bone, cartilage and soft tissue. Front Radiat Ther Oncol 23: 221-237; 251-254, 1989.

12. Poland JM: The role of Candida infections as an adverse effect upon head and neck cancer patients undergoing therapeutic radiation and the effect of antimycotic treatment. Mycoses 32 (Suppl 2): 39-41, 1989.

13. Parker RG: Radiation-induced cancer as a factor in clinical decision making (the 1989 ASTRO Gold Medal address). Int J Radiat Oncol Biol Phys 18: 993-1000, 1990.

14. Larson DL: Management of complications of radiotherapy of the head and neck. Surg Clin North Am 66: 169-182, 1986.
15. Affolter A, Schmidtmann I, Mann WJ and Brieger J: Cancerassociated fibroblasts do not respond to combined irradiation and kinase inhibitor treatment. Oncol Rep 29: 785-790, 2013.

16. Tsai KK, Chuang EY, Little JB and Yuan ZM: Cellular mechanisms for low-dose ionizing radiation-induced perturbation of the breast tissue microenvironment. Cancer Res 65: 6734-6744, 2005

17. Gehrke T, Scherzad A, Hackenberg S, Schenzielorz P, Hagen R and Kleinsasser N: Differences in tumor stroma derived from irradiated versus non-irradiated fibroblasts in a co-culture model with head and neck squamous cell carcinoma. Oncol Lett 12: 3549-3554, 2016.

18. Vangipuram M, Ting D, Kim S, Diaz R and Schule B: Skin punch biopsy explant culture for derivation of primary human fibroblasts. J Vis Exp: e3779, 2013.

19. Mosmann T: Rapid colorimetric assay for cellular growth and survival: Application to proliferation and cytotoxicity assays. J Immunol Methods 65: 55-63, 1983

20. Liotta LA and Kohn EC: The microenvironment of the tumour-host interface. Nature 411: 375-379, 2001.

21. Ronnov-Jessen L, Petersen OW and Bissell MJ: Cellular changes involved in conversion of normal to malignant breast: Importance of the stromal reaction. Physiol Rev 76: 69-125, 1996.

22. Ohlund D, Elyada E and Tuveson D: Fibroblast heterogeneity in the cancer wound. J Exp Med 211: 1503-1523, 2014.

23. Ostman A and Augsten M: Cancer-associated fibroblasts and tumor growth-bystanders turning into key players. Curr Opin Genet Dev 19: 67-73, 2009.

24. Marsh T, Pietras K and McAllister SS: Fibroblasts as architects of cancer pathogenesis. Biochim Biophys Acta 1832: 1070-1078, 2013.

25. Kalluri R: The biology and function of fibroblasts in cancer. Nat Rev Cancer 16: 582-598, 2016.

26. Lyng FM, O'Reilly S, Cottell DC, Seymour CB and Mothersill C: Persistent expression of morphological abnormalities in the distant progeny of irradiated cells. Radiat Environ Biophys 35: 273-283, 1996.

27. Chang WP and Little JB: Delayed reproductive death as a dominant phenotype in cell clones surviving $X$-irradiation. Carcinogenesis 13: 923-928, 1992.

28. Chang WP and Little JB: Delayed reproductive death in X-irradiated Chinese hamster ovary cells. Int J Radiat Biol 60: 483-496, 1991.

29. Gorgojo L and Little JB: Expression of lethal mutations in progeny of irradiated mammalian cells. Int J Radiat Biol 55: 619-630, 1989.

30. Chatterjee A, Hodgkiss RJ and Rojas A: Contribution of lethal mutations to excision assays for tumour cell survival. Acta Oncol 34: 493-498, 1995.

31. O'Reilly S, Mothersill C and Seymour CB: Postirradiation expression of lethal mutations in an immortalized human keratinocyte cell line. Int J Radiat Biol 66: 77-83, 1994.

32. Kadhim MA, Macdonald DA, Goodhead DT, Lorimore SA, Marsden SJ and Wright EG: Transmission of chromosomal instability after plutonium alpha-particle irradiation. Nature 355: 738-740, 1992.

33. Alessio N, Bohn W, Rauchberger V, Rizzolio F, Cipollaro M, Rosemann M, Irmler M, Beckers J, Giordano A and Galderisi U: Silencing of RB1 but not of RB2/P130 induces cellular senescence and impairs the differentiation potential of human mesenchymal stem cells. Cell Mol Life Sci 70: 1637-1651, 2013.

34. Cmielova J, Havelek R, Soukup T, Jiroutová A, Visek B, Suchánek J, Vavrova J, Mokry J, Muthna D, Bruckova L, et al: Gamma radiation induces senescence in human adult mesenchymal stem cells from bone marrow and periodontal ligaments. Int J Radiat Biol 88: 393-404, 2012.

35. Rodriguez-Menocal L, Shareef S, Salgado M, Shabbir A and Van Badiavas E: Role of whole bone marrow, whole bone marrow cultured cells, and mesenchymal stem cells in chronic wound healing. Stem Cell Res Ther 6: 24, 2015.

36. Henke A, Franco OE, Stewart GD, Riddick AC, Katz E, Hayward SW and Thomson AA: Reduced contractility and motility of prostatic cancer-associated fibroblasts after inhibition of heat shock protein 90. Cancers (Basel) 8: E77, 2016.

37. Nicolay NH, Sommer E, Lopez R, Wirkner U, Trinh T, Sisombath S, Debus J, Ho AD, Saffrich R and Huber PE: Mesenchymal stem cells retain their defining stem cell characteristics after exposure to ionizing radiation. Int J Radiat Oncol Biol Phys 87: 1171-1178, 2013.

38. Kamochi N, Nakashima M, Aoki S, Uchihashi K, Sugihara H, Toda S and Kudo S: Irradiated fibroblast-induced bystander effects on invasive growth of squamous cell carcinoma under cancer-stromal cell interaction. Cancer Sci 99: 2417-2427, 2008. 
39. Ohuchida K, Mizumoto K, Murakami M, Qian LW, Sato N, Nagai E, Matsumoto K, Nakamura T and Tanaka M: Radiation to stromal fibroblasts increases invasiveness of pancreatic cancer cells through tumor-stromal interactions. Cancer Res 64: 3215-3222, 2004.

40. Barcellos-Hoff MH and Ravani SA: Irradiated mammary gland stroma promotes the expression of tumorigenic potential by unirradiated epithelial cells. Cancer Res 60: 1254-1260, 2000.

41. Harigai M, Hara M, Kitani A, Norioka K, Hirose T, Hirose W, Suzuki K, Kawakami M, Masuda K, Shinmei M, et al: Interleukin 1 and tumor necrosis factor-alpha synergistically increase the production of interleukin 6 in human synovial fibroblast. J Clin Lab Immunol 34: 107-113, 1991.

42. Lu C, Vickers MF and Kerbel RS: Interleukin 6: A fibroblast-derived growth inhibitor of human melanoma cells from early but not advanced stages of tumor progression. Proc Nat Acad Sci USA 89: 9215-9219, 1992.
43. Anderson IC, Mari SE, Broderick RJ, Mari BP and Shipp MA: The angiogenic factor interleukin 8 is induced in non-small cell lung cancer/pulmonary fibroblast cocultures. Cancer Res 60: 269-272, 2000.

44. Doldi V, Callari M, Giannoni E, D'Aiuto F, Maffezzini M, Valdagni R, Chiarugi P, Gandellini P and Zaffaroni N: Integrated gene and miRNA expression analysis of prostate cancer associated fibroblasts supports a prominent role for interleukin- 6 in fibroblast activation. Oncotarget 6: 31441-31460, 2015. 